\title{
Sexual violence and eclampsia: analysis of data from Demographic and Health Surveys from seven low- and middle-income countries
}

\author{
Saverio Bellizzi ${ }^{1}$, Alessandra Nivoli ${ }^{2}$, \\ Paola Salaris ${ }^{3}$, Anna Rita Ronzoni ${ }^{4}$, \\ Giuseppe Pichierri ${ }^{5}$, Francesca \\ Palestra $^{6}$, Ola Wazway ${ }^{7}$, Miguel Angel \\ Luque-Fernandez ${ }^{8,9,10}$ \\ ${ }^{1}$ Partnership for Maternal, Newborn \& Child \\ Health, Geneva, Switzerland \\ ${ }^{2}$ Department of Neuroscience, Institute of \\ Psychiatry, University of Sassari, Sassari, Italy \\ ${ }^{3}$ Department of Endocrinology, Mater Olbia \\ Hospital, Olbia, Italy \\ ${ }^{4}$ World Health Organization, Cairo, Egypt \\ ${ }^{5}$ Kingston Hospital NHS Foundation Trust, \\ Galsworthy Road, Kingston upon Thames, UK \\ ${ }^{6}$ World Health Organisation, Addis Ababa, \\ Ethiopia \\ ${ }^{7}$ Partnership for Maternal, Newborn \& Child \\ Health, Geneva, Switzerland \\ ${ }^{8}$ Department of Non-Communicable Disease \\ Epidemiology, Faculty of Epidemiology and \\ Population Health, London School of Hygiene \\ and Tropical Medicine, London, UK \\ ${ }^{9}$ Department of Epidemiology, Harvard T.H. Chan \\ School of Public Health, Boston, Massachusetts, \\ USA \\ ${ }^{10}$ Biomedical Research Institute of Granada, \\ Non-Communicable and Cancer Epidemiology \\ Group (ibs.Granada), Andalusian School of \\ Public Health, Granada, University of Granada, \\ Spain
}

\section{Correspondence to:}

Saverio Bellizzi, MD, MSc, PhD

World Health Organization

Partnership for Maternal, Newborn \& Child Health

20 Avenue Appia

1202 Geneva

Switzerland

bellizzis@who.int
Background Scientific literature has provided clear evidence of the profound impact of sexual violence on women's health, such as somatic disorders and mental adverse outcomes. However, consequences related to obstetric complications are not yet completely clarified. This study aimed to assess the association of lifetime exposure to intimate partner sexual violence with eclampsia.

Methods We considered all the seven Demographic and Health Surveys (DHS) that included data on sexual violence and on signs and symptoms suggestive of eclampsia for women of reproductive age (15-49 years). We computed unadjusted and adjusted odds ratios (OR) to evaluate the risk of suggestive eclampsia by ever subjected to sexual violence. A sensitivity analysis was conducted restricting the study population to women who had their last live birth over the 12 months before the interview.

Results Self-reported experience of sexual violence ranged from $3.7 \%$ in Mali to $9.2 \%$ in India while prevalence of women reporting signs and symptoms compatible with eclampsia ranged from $14.3 \%$ in Afghanistan to $0.7 \%$ in the Philippines. Reported sexual violence was associated with a 2-fold increased odd of signs and symptoms suggestive of eclampsia in the pooled analysis. The sensitivity analysis confirmed the strength of the association between sexual violence and eclampsia in Afghanistan and in India.

Conclusions Women and girls in low-and-middle-income countries are at high risk of sexual violence, which may represent a risk factor for hypertensive obstetric complication. Accurate counseling by health care providers during antenatal care consultations may represent an important opportunity to prevent adverse outcomes during pregnancy.
Violence against women has globally been recognized as a significant human right issue [1] and, as defined by the WHO, a "global health problem of epidemic proportions" [2].

Available estimates indicate that around one-third of women worldwide throughout the world will experience physical and/or sexual violence by a partner or sexual violence by a non-partner [3].

Similarly, around one in 3 women who have been in a relationship report that they have experienced some form of physical and /or sexual violence by their intimate partner in their lifetime [3]. 
Studies carried in different settings have clearly demonstrated an adverse effect of sexual violence on women's health [4], which stretches from somatic disorders like chronic pelvic pain [5], to mental adverse outcomes like depression and anxiety [6-8]. Yet, dearth of evidence exists on the impact of experienced sexual violence on labour distress later in life, with very few studies reporting contradictory results on an increased risk of dystocia [9-12]. Another recent report based on prospective data from a Rape Trauma Service (RTS) evidenced an association with obstetric outcomes like antepartum bleeding [13].

Pre-eclampsia occurs in around 2\%-8\% of all pregnancies [14] and represents one of the major challenges for researchers in terms of etiology and physiological mechanisms; however, the central role of the placenta in its pathogenesis is undisputed [15]. To explain the significant association between intimate partner violence (IPV) during pregnancy and maternal hypertension [16-18], scientists have speculated on behavioral, emotional, and biological mechanisms related to the sexual aggression trauma [19]; more specifically, alterations of specific hormone synthesis and uptake at placental level was claimed to play a key role [18].

We conducted a secondary analysis of national Demographic Health Survey data from seven countries to assess the association between reported lifetime sexual violence and the occurrence of signs and symptoms suggestive of eclampsia around childbirth during the last pregnancy. These data were from Afghanistan (2015), Colombia (2015), India (2005), Mali (2006), Peru (2012), Philippines (2008), Sao Tome and Principe (2008/2009).

Countries under study represent a heterogeneous sample of contexts in relation to the occurrence of sexual violence as well aspects related to the prevention and treatment of preeclampsia/eclampsia.

Afghanistan for instance feature characteristics like conflict and patriarchal culture, especially in rural areas, both associated with very high levels of violence against women [20]. In the recent years there has been increasing recognition that was exacerbates violence against women and girls, with abuses remaining high also in the post-conflict period [21].

On the other hand, Colombia has made substantial progress toward establishing laws protecting women's right, including the landmark Law 1257, adopted in 2008, which issued regulations to prevent and punish violence and discrimination against women [22]. However, IPV remains a major issue and an estimated 32\% of ever-partnered Colombian women aged 13-49 have experienced physical violence from their current or last intimate partner [22]. Colombia had also the second highest 12-month prevalence rate of physical partner violence in a comparative analysis of 12 Latin American countries [22]. Similarly, in Peru violence against women is a widespread issue with about half of women aged between 15 and 49 who have experienced violence from their partners [23].

India shows one of the lowest prevalence (8.5\%) of sexual violence in the world; however, this translates into more that 27 million affected [24]. Important to note how only $1 \%$ of victims of sexual violence report the crime to the police, perhaps due to the fact that marital rape is not a crime in India and most of the sexual violence episodes occur in marriage [24].

Prevalence of sexual violence is most probably underestimated also in countries like Sao Tome and Principe and Mali, where occurrence is particularly focalized towards students and housewives [25]. Finally, In the Philippines, statistics report that 1 in 20 women and girls age 15-49 have experienced sexual violence in their lifetime [26].

As far as eclampsia is concerned, Afghanistan has one of the highest burdens of maternal mortality in the world, estimated at 789 deaths per 100000 live births, and hypertensive disorders account for around one fifth of maternal deaths [27]. Detailed analysis of data from 1980 to 2015 has shown no reduction in incidence of eclampsia in India over the last few decades [28]. Finally, a 2017 multicountry analysis has highlighted a prevalence of signs and symptoms compatible with eclampsia as low as 1.2 (95\% confidence interval $\mathrm{CI}=1.0-1.3$ ) in the Latin American WHO Region (Peru and Colombia) and a proportion as high as 2.5 (95\% CI $=2.3-2.7)$ in the African WHO Region, which included also Mali [29].

\section{METHODS}

\section{Population, setting and data}

DHS are nationally representative random household surveys covering several indicators of population, with particular focus on maternal and child health [30]. All or ever-married women of reproductive age (15-49 years) are the target population in most DHS surveys. DHS guidelines are designed to maximize 
safety and disclosure, including interviewing only one woman per household, and maintaining complete privacy during the interview [31]. Questionnaire are translated into major local languages and data are collected via face-to-face interviews by trained personnel. In order to maximize the information comparability across countries, the core content for every round of DHS is standard and includes a complete birth and death history for the children of each eligible woman. Additional questions related to pregnancy complications may also be adopted by countries from the survey questionnaire on antenatal, childbirth and postnatal care.

Several countries comprise a specific questionnaire module on exposure to intimate partner violence (IPV), which is measured by binary indicators of physical, sexual, and emotional violence [32]. Information about IPV is collected with no-one else in the household aware that this was done. The violence module is an abbreviated and modified version of the Conflict Tactics Scale [33], which classifies specific acts like "twisting your arm" as physical, emotional, or sexual violence. Ever having experienced any form of violence by their husband or partner and by their most recent husband or partner is respectively obtained from married/cohabiting and formerly married/cohabiting women [32].

Our analysis included only the most recent surveys in these countries presenting data on both IPV and reported life-threatening obstetric complications during birth of the last infant, thus limiting our analysis to one birth per woman.

We pooled all the seven DHS national data sets into one cross-sectional data set containing 247140 women of reproductive age. We excluded data on girls under the age of 15 and on women not interviewed for domestic violence because of reasons like not meeting eligibility criteria $(n=65275)$. For our analysis we only considered the latest pregnancy that occurred within the three years prior to the survey, thus excluding 129078 women; after excluding records with missing data on convulsions $(n=1429)$ and on covariates of interest $(n=406)$ as well as twin pregnancies [34] $(n=204)$, the final analysis consisted of 50748 individuals (Figure 1).

\section{Main outcome, exposure and other variables}

We used women self-reported occurrence of convulsions not caused by fever as a proxy for the outcome (eclampsia) and women self-reported sexual violence by the partner as the exposure. As indicated by the World Health Organization [35], Intimate Partner Violence (IPV) refers to ongoing or past violence and abuse by an intimate partner or ex-partner - a husband, boyfriend or lover, either current or past. Women may suffer several types of violence by a male partner: physical violence, emotional/psychological abuse, controlling behaviours, and sexual violence.

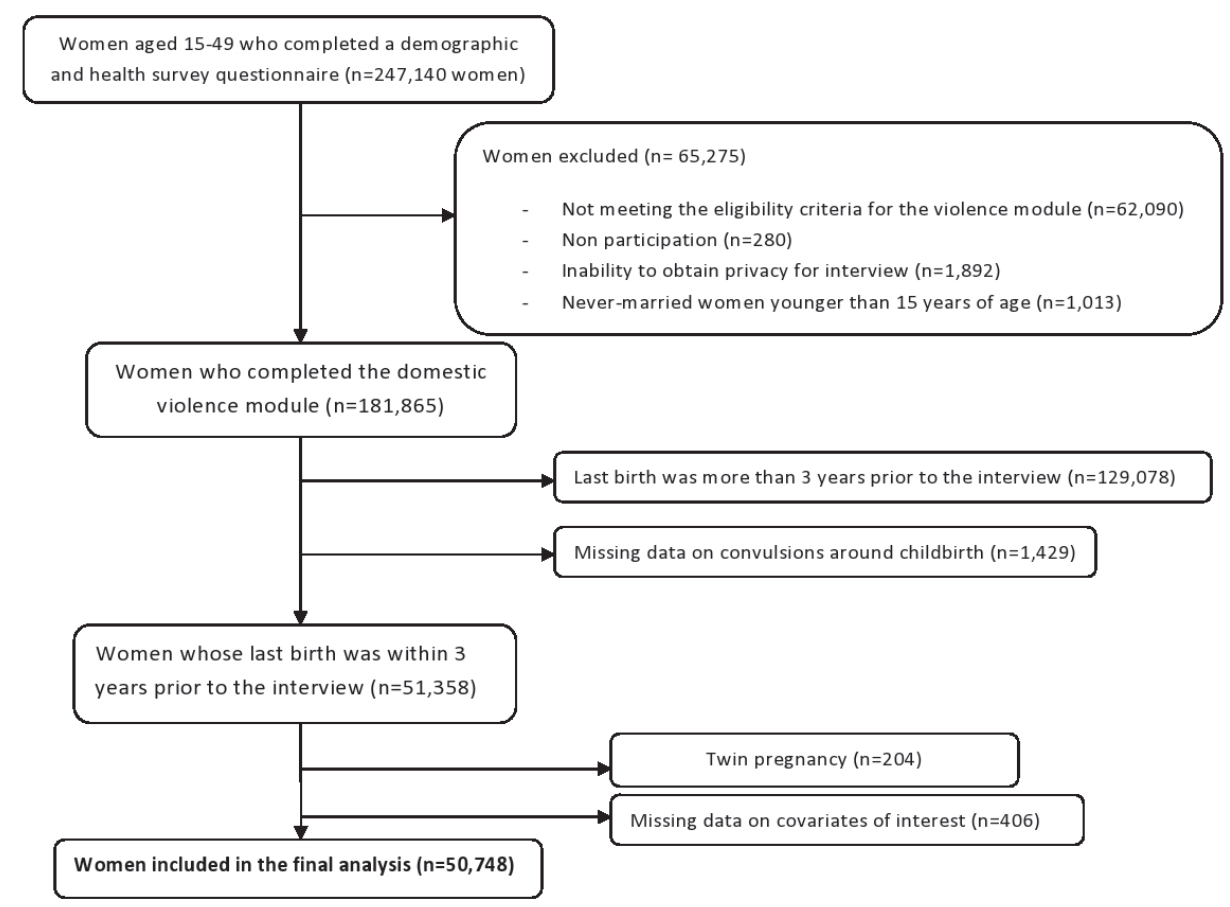

Figure 1. Study participants flowchart. 


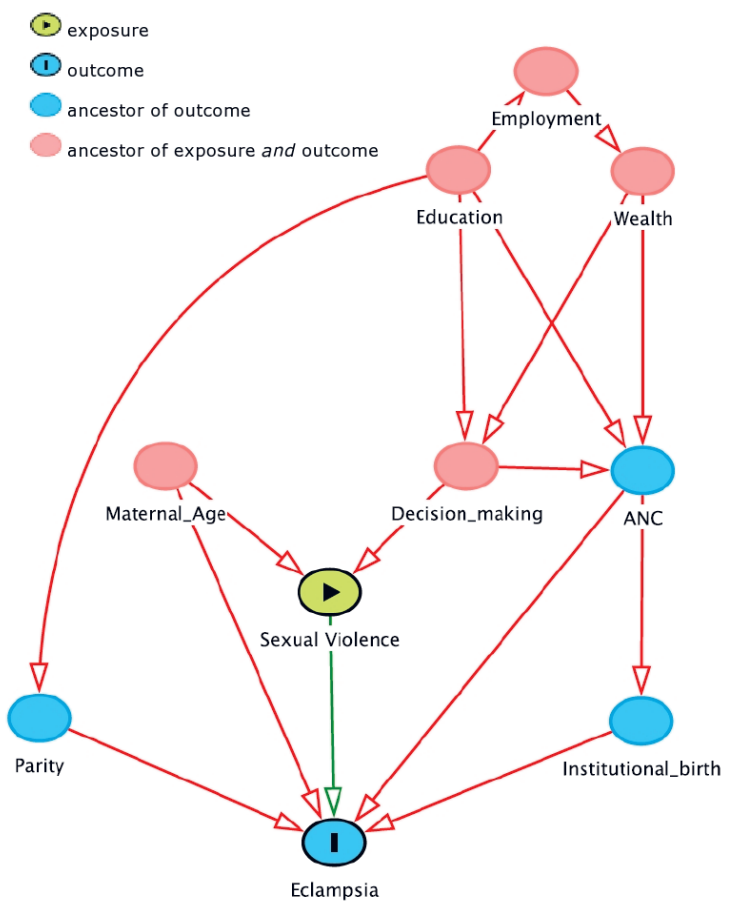

Figure 2. Directed acyclic graph for a proposed causal framework in the association between sexual violence and eclampsia.
The index pregnancy corresponds with the closest pregnancy to the DHS interview in case of multiple pregnancies women.

We explored several covariates. Maternal age was categorized into three groups, from age 15 to age 24 , from age 25 to age 36 , and from age 37 to age 49; place of residence was split into urban and rural settings; a wealth index based on asset-ownership and household characteristics data (categorized using the quintiles "poorest", "poorer", "middle", "richer", and "richest") was considered as a proxy for socio-economic status [36]. As for literature [37], both maternal and partner's educational attainment were included after classification in "no education", "primary", "secondary", and "higher". In consideration of the reported strong association with both maternal hypertensive complications and violence, access to antenatal care and institutional birth as well as self-decision for her own health care (proxy for woman empowerment) were explored [38-40]. We did not consider intendedness of pregnancy as it lies on the causal pathway. Finally, maternal employment status ("employed" and "unemployed") and birth order categorized in "first birth" and "latter birth" [31] were investigated. We considered all these variables as potential confounders and adjusted for them when assessing the association between eclampsia and sexual violence (Figure 2) [38-42].

\section{Statistical analysis}

We use counts and percentages to describe the prevalence of eclampsia and sexual violence by DHS countries. We also described the distribution of reported sexual violence by each covariate.

We evaluated the prevalence of eclampsia and sexual violence across the levels of the covariates in the analysis using crosstabulations and computed the $\mathbf{x}^{2}$ or Fisher exact and trend $P$ value tests. Then, to evaluate the risk of suggestive eclampsia by ever subjected to sexual violence we computed unadjusted and adjusted odds ratios (OR) for each country and for the pooled sample. We used a logistic regression. For multivariable analysis, we adjusted for (maternal age, residence, wealth, maternal and partner education, access to ANC and institutional birth, decision making on own health, and parity) and explored the interactions between the occurrence of sexual violence and parity. Considering the lack of information on the exact timing of sexual violence, we conducted a sensitivity analysis restricting our study population to women who had their last live birth over the 12 months before the interview.

Finally, we explored between and within countries heterogeneity for the pooled association between eclampsia and sexual violence and used a nonlinear mixed logistic random effect model to control for the within-country correlation [43].

Confidence interval were calculated using bootstrap technique, based on person-to-person variability (eg, Neyman-Pearson null hypothesis).

We used Stata v13.1 SE (StataCorp LP, College Station, Texas, USA) [44] for statistical analysis.

\section{Ethical approval}

This study used existing data obtained from ORC Macro through formal request mechanisms. No additional ethical review for the secondary analysis was required since each country and the institutional review board of ORC Macro (Calverton, MD, USA) approved the DHS data collection procedures.

\section{RESULTS}

Of the 50748 women in the seven countries with available data in their Demographic and Health Surveys, the prevalence of self-reported experience of sexual violence was $7.7 \%(\mathrm{n}=3908)$, ranging from $3.7 \%(\mathrm{n}=201)$ in Mali to 9.2\% ( $\mathrm{n}=1876)$ in India (Table 1$)$. A similar prevalence of women self-reported convulsions with no fever around childbirth $(7.9 \% ; n=4026)$, ranging from $14.3 \%(n=11669)$ in Afghanistan (the highest prevalence) to $0.7 \%(\mathrm{n}=2737)$ in the Philippines (the lowest prevalence) (Table 1 ). 
There were no differences in self-reported sexual violence by categories of age. However, it was more common in rural areas. A clear significant linear trend appeared when assessing wealth and education, with the fewer sexual assaults for richest and the higher educated mothers (Table 2). A significantly higher prevalence of sexual evidence was present for women with no ANC consultations, no institutional birth, successive birth order position, and for women who could not decide autonomously for their health.

Reported sexual violence was associated with a 2-fold increased odd of signs and symptoms suggestive of eclampsia in the pooled analysis when adjusted for all the above-mentioned factors. In the individual country analyses, there was a significant association between sexual violence and eclampsia in Afghanistan, Colombia, India, and Mali (Table 3, Figure 3).

In the subgroup analyses of pooled data for last pregnancy within 12 months prior to the interview, the odds of eclampsia signs and symptoms decreased to $1.8(95 \% \mathrm{CI}=1.1-2.8)$, and remained significant for Afghanistan, Colombia and India, while no data were available for Mali and Sao Tome and Principe (Table 4).

Table 1. Prevalence of sexual violence and eclampsia during the last pregnancy in Afghanistan, Colombia, India, Mali, Peru, Philippines, and Sao Tome and Principe, between 2005 and 2015, n=50 578

\begin{tabular}{|c|c|c|c|c|c|}
\hline \multirow[t]{2}{*}{ Counthy } & \multicolumn{2}{|c|}{ Sexual violence } & \multicolumn{2}{|c|}{ ECLAMPSIA } & \multirow{2}{*}{$\begin{array}{c}\text { TOTAL } \\
\mathrm{N} \\
\end{array}$} \\
\hline & $\mathbf{n}$ & $\%$ & $\mathbf{n}$ & $\%$ & \\
\hline Afghanistan 2015 & 997 & 8.5 & 1,670 & 14.3 & 11669 \\
\hline Colombia 2015 & 275 & 4.9 & 69 & 1.2 & 5569 \\
\hline India 2005 & 1876 & 9.2 & 2,054 & 10.1 & 20289 \\
\hline Mali 2006 & 201 & 3.7 & 146 & 2.7 & 5415 \\
\hline Peru 2012 & 260 & 6.2 & 42 & 1.0 & 4200 \\
\hline Philippines 2008 & 241 & 8.8 & 20 & 0.7 & 2737 \\
\hline Sao Tome 2008/09 & 58 & 6.7 & 25 & 2.9 & 869 \\
\hline Total & 3908 & 7.7 & 4,026 & 7.9 & 50758 \\
\hline
\end{tabular}

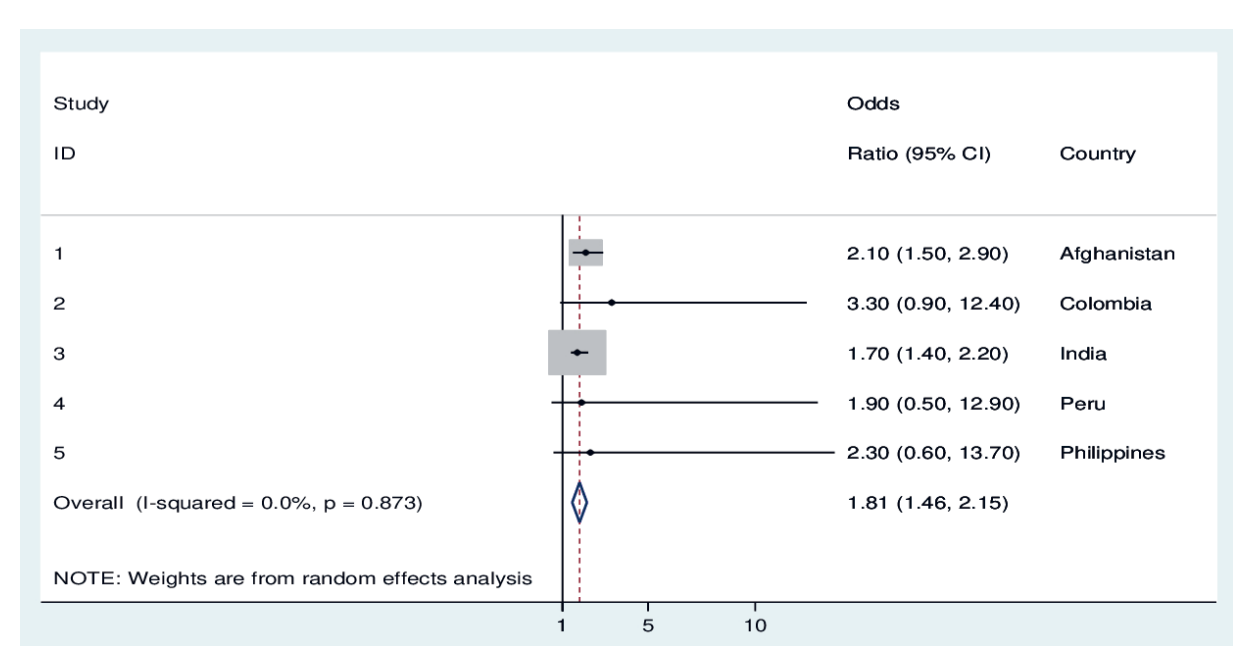

Figure 3. Forest plot showing the association between exposure to sexual violence and signs and symptoms suggestive of eclampsia around childbirth for pregnancies in the previous 12 months, by DHS country (Afghanistan, Colombia, India, Peru, and the Philippines) between 2005 and $2015, \mathrm{n}=19881$.

\section{DISCUSSION}

We found strong evidence supporting the association between the self-reported occurrence of convulsions not caused by fever and women self-reported sexual violence by partner among pregnant women in seven low-and-middle-income countries. Furthermore, this secondary analysis indicated that almost one in ten women in the low-and-middle-income countries under analysis had a history of sexual violence and had their last pregnancy complicated with signs and symptoms compatible with eclampsia. Pooled analysis showed 2-fold higher risk for eclampsia among women who reported lifetime sexual aggression when compared to women with no history of violence after adjusting for all the relevant confounders. 
Table 2. Descriptive characteristics of interviewees and association with sexual violence in Afghanistan, Colombia, India, Mali, Peru, Philippines, and Sao Tome and Principe, between 2005 and 2015, $\mathrm{n}=50578$

\begin{tabular}{|c|c|c|c|c|}
\hline \multirow[t]{2}{*}{ Variable } & \multicolumn{4}{|c|}{$\begin{array}{l}\text { REPORTING SEXUAL } \\
\text { VIOLENCE }\end{array}$} \\
\hline & Total & $\mathbf{n}$ & $\%$ & $P$-value \\
\hline \multicolumn{5}{|l|}{ Age in years: } \\
\hline $15-24$ & 18290 & 1414 & 7.7 & 0.7 \\
\hline $25-36$ & 24826 & 1916 & 7.7 & \\
\hline $37-49$ & 7632 & 578 & 7.6 & \\
\hline \multicolumn{5}{|l|}{ Residence: } \\
\hline Urban & 20015 & 1201 & 6.0 & $<0.001$ \\
\hline Rural & 30723 & 2707 & 8.8 & \\
\hline \multicolumn{5}{|l|}{ Wealth quintile: } \\
\hline Poorest & 11261 & 1231 & 10.9 & $<0.001$ \\
\hline Poorer & 11351 & 1014 & 8.9 & \\
\hline Middle & 10569 & 812 & 7.7 & \\
\hline Richer & 9850 & 562 & 5.7 & \\
\hline Richest & 7717 & 289 & 3.7 & \\
\hline \multicolumn{5}{|l|}{ Education level: } \\
\hline None & 23031 & 2140 & 9.3 & $<0.001$ \\
\hline Primary & 7972 & 699 & 8.8 & \\
\hline Secondary & 14803 & 913 & 6.2 & \\
\hline Higher & 4942 & 156 & 3.2 & \\
\hline \multicolumn{5}{|c|}{ Partner's education: } \\
\hline None & 15937 & 1375 & 8.6 & $<0.001$ \\
\hline Primary & 7686 & 702 & 9.1 & \\
\hline Secondary & 16670 & 1289 & 7.7 & \\
\hline Higher & 4486 & 220 & 4.9 & \\
\hline \multicolumn{5}{|c|}{ Employment status: } \\
\hline Employed & 20645 & 1539 & 8.4 & 0.08 \\
\hline Unemployed & 29253 & 2369 & 8.6 & \\
\hline \multicolumn{5}{|l|}{ ANC: } \\
\hline None & 10947 & 1045 & 9.5 & $<0.001$ \\
\hline At least one & 39770 & 2860 & 7.2 & \\
\hline \multicolumn{5}{|c|}{ Woman empowerment: } \\
\hline No & 23594 & 2039 & 8.6 & $<0.001$ \\
\hline Yes & 27154 & 1869 & 6.9 & \\
\hline \multicolumn{5}{|c|}{ Institutional birth: } \\
\hline No & 22732 & 2191 & 9.6 & $<0.001$ \\
\hline Yes & 28016 & 1717 & 6.1 & \\
\hline \multicolumn{5}{|l|}{ Parity: } \\
\hline First birth & 12304 & 731 & 5.9 & $<0.001$ \\
\hline Second or more & 38444 & 3177 & 8.3 & \\
\hline
\end{tabular}

ANC - antenatal care
DHS are frequently the only source of maternal health information in low- and middle-income countries [30] and are generally considered of high-quality because of standardized questionnaires and operative procedures [30]. However, the use of cross-sectional data makes it difficult to know whether the sexual violence occurred before pregnancy or vice versa. We attempted to minimize such a problem by restricting the analysis to the last pregnancy taking place within three years prior to the interview; to confirm results, we conducted a sensitivity analysis considering only last pregnancy in the previous 12 months.

Under-reporting violence victimization and perpetration is common in this type of surveys due to recall and reporting bias, which leads to non-disclosure of violent behaviors [4]. The survey methodology was conceived to reduce the reporting bias but could not eliminate it entirely. There is also a possible under-reporting by older women who may have forgotten a violence experienced many years ago. Despite it, a hospital-based study found that recall of convulsions was prone to little inaccuracy (sensitivity $=96.4 \%$; specificity $=87.5 \%$ ) when compared to the recall of other signs and symptoms of complications, we cannot completely rule out a bias effect [45]. Furthermore, women who experienced violence may be more likely to report adverse pregnancy outcomes [46].

Given that women who experience violence may be more likely to terminate their pregnancy than women who do no, a differential selection bias towards the null may have been introduced [47]. Moreover, for some reasons some women were not interviewed; research showed that women refusing to be interviewed are more likely to have experienced adverse pregnancy outcomes [48].

Also, we could not adjust for unmeasured confounding factors such as alcohol intake or drug use, which have frequently been associated to history of abuse [49].

Violence against women has lately been gaining the deserved attention for the long-term consequences on physical and mental health. Very few analyses reported on the association between sexual aggression and pregnancy complications around childbirth $[13,50,51]$, and to our knowledge, no study explored the effect on maternal hypertensive disorders as a primary objective.

The high variability of eclampsia prevalence across countries has been highlighted in the past. One health facility-based study in particular showed values ranging from less than 1\% in Angola up to 8\% in Brazil

Table 3. Association between exposure to sexual violence and signs and symptoms suggestive of eclampsia around childbirth for pregnancies in the previous three years by DHS country (Afghanistan, Colombia, India, Mali, Peru, Philippines, and Sao Tome and Principe), between 2005 and 2015, n=50578.

\begin{tabular}{lcccccc} 
Country & $\mathbf{N o}, \mathbf{n}(\%)$ & Yes, $\mathbf{n}(\%)$ & cOR & 95\% CI & aOR & 95\% CI \\
\hline Afghanistan & $1495(89.5)$ & $175(10.5)$ & 1.3 & $1.1-1.6$ & 1.6 & $1.2-2.2$ \\
\hline Colombia & $63(91.3)$ & $6(8.7)$ & 1.8 & $0.7-4.4$ & 2.3 & $1.0-5.7$ \\
\hline India & $1751(85.2)$ & $303(14.8)$ & 1.8 & $1.5-2.3$ & 1.6 & $1.3-1.9$ \\
\hline Mali & $128(87.7)$ & $18(12.3)$ & 3.9 & $2.2-6.5$ & 4.5 & $2.4-8.4$ \\
\hline Peru & $36(85.7)$ & $6(14.3)$ & 2.6 & $1.1-6.2$ & 2.1 & $0.9-5.8$ \\
\hline Philippines & $17(85.0)$ & $3(15.0)$ & 1.8 & $0.4-6.4$ & 1.2 & $0.3-5.9$ \\
\hline Sao Tome and Principe & $23(92.0)$ & $2(8.0)$ & 1.2 & $0.3-5.4$ & 1.4 & $0.6-3.4$ \\
\hline All countries & $3513(87.2)$ & $513(12.8)$ & 1.7 & $1.3-2.3$ & 2.0 & $1.5-2.8$ \\
\hline
\end{tabular}

$\mathrm{COR}$ - crude odds ratio, aOR - adjusted odds ratio for maternal age, residence, wealth, maternal and partner education, access to antenatal care (ANC) and institutional birth, decision making on own health, and parity, CI - confidence interval 
Table 4. Association between exposure to sexual violence and signs and symptoms suggestive of eclampsia around childbirth for pregnancies in the previous 12 mo by DHS country (Afghanistan, Colombia, India, Peru, and the Philippines) between 2005 and 2015, n=19881

\begin{tabular}{lcccccc} 
Country & No, $\mathbf{n}(\%)$ & Yes, $\mathbf{n}(\%)$ & cOR & 95\% CI & aOR & 95\% CI \\
\hline Afghanistan & $598(89.7)$ & $69(10.4)$ & 1.5 & $1.1-2.0$ & 2.1 & $1.4-2.9$ \\
\hline Colombia & $20(87.0)$ & $3(13.0)$ & 4.3 & $1.2-14.8$ & 3.3 & $0.8-12.5$ \\
\hline India & $725(84.2)$ & $136(15.8)$ & 2.0 & $1.6-2.4$ & 1.7 & $1.4-2.4$ \\
\hline Peru & $13(86.7)$ & $2(13.3)$ & 3.2 & $0.7-14.5$ & 1.9 & $0.5-12.9$ \\
\hline Philippines & $10(76.9)$ & $3(23.1)$ & 3.4 & $0.9-12.8$ & 2.3 & $0.6-13.7$ \\
\hline All countries & $1427(87.0)$ & $214(13.0)$ & 1.5 & $1.1-1.9$ & 1.8 & $1.1-2.8$ \\
\hline
\end{tabular}

COR - crude odds ratio, aOR - adjusted odds ratio for maternal age, residence, wealth, maternal and partner education, access to antenatal care (ANC) and institutional birth, decision making on own health, and parity, CI - confidence interval

[52]. High prevalence of hypertensive maternal disorders might reflect various aspects, such as variability in maternal risk-factor distribution and poor access to health care services leading to poor management of obstetric complications.

Our results on maternal and pregnancy factors linked to sexual violence are largely confirmed in literature. Woman and partner's lowest level of education [37], unintendedness of pregnancy [38], and lack of decision making on own health care are all clearly associated with abuse [38,39]. Women who experienced sexual assault generally have inadequate antenatal care [40] and less access to institutional birth [38]. Decision making, here considered as who makes decisions about her own health care, is associated with sexual violence.

A case-control study conducted in Peru found an increased risk of pre-eclampsia for women reporting intimate partner physical and emotional violence ( $\mathrm{OR}=1.9 ; 95 \% \mathrm{CI}=1.1-3.5)$ during pregnancy [18]. Other two studies investigating the effects of intimate partner violence (IPV) around the time of pregnancy $[16,17]$ confirmed an association with hypertension during pregnancy. On the other side, a prospective cohort including 68505 women from fourteen US states revealed that women exposed to sexual violence before age 18 were more likely to develop hypertension compared to women with no abuse history [53]. Although pre-eclampsia was not the primary outcome under study, a report found its prevalence higher among women reporting childhood abuse, $5.0 \%$ compared with $4.2 \%$ among those not reporting childhood abuse ( $P$ value $=0.013$ ) [53]. Similar results were evidenced in a study investigating on the association between childhood abuse and autism [54].

Abuse before pregnancy may increase the risk of maternal hypertensive disorders through stress, behavioral, or other pathways. Stressful events like sexual violence before pregnancy may lead to conditions like kidney or urinary tract infection, placental problems, gestational diabetes [16], augmented inflammatory markers [55], and autoimmune conditions [56], all conditions related to hypertension during pregnancy [41]. Distress conditions, including intimate partner violence, may directly change the hypothalamic-pituitary-adrenal (HPA) axis, leading to increased cortisol levels [57,58]. Endogenous hypercortisolism as in the case of the Cushing syndrome on its turn, has been found to be associated with hypertensive disorders during pregnancy, including eclampsia [59]. Mechanisms leading to maternal hypertension include alterations such as endothelial dysfunction [60], impaired placental circulaton [61], and altered activity of 11 beta-hydroxysteroid dehydrogenase that inactivates cortisol in cortisone [62]. Recent reports focused the attention to the altered expression of cortisol-signaling genes as an important regulatory mechanism related to the epigenetic modification in the placenta and subsequent evolution to pre-eclampsia [63]. Other metabolic alternations like reduced heart rate variability and parasympathetic tone have been implicated in the pathogenesis anxiety disorders/depression, often linked to IPV, and pre-eclampsia [64].

\section{CONCLUSIONS}

The augmented risk of hypertensive obstetric complications reinforces the literature findings on maternal health consequences due to exposure to intimate partner sexual violence. As highlighted by the WHO [65], antenatal care may represent an important opportunity to ask women about violence. This entails enhanced counseling by health care providers when assessing pregnancy-related health complaints, and close monitoring during the third trimester due to higher chances of adverse outcomes. 
Disclaimer: The findings and conclusions in this report are those of the authors and do not necessarily represent the views of the funding agencies. The corresponding author had full access to all the data in the study and had final responsibility for the decision to submit for publication.

Availability of data and materials: The datasets used in this study were obtained from the DHS program thanks to the authorization received to download the dataset on the website (https://dhsprogram.com/data/available-datasets.cfm).

Funding: None.

Authorship contributions: SB developed the concept and design of the study. SB carried out the analysis and wrote the manuscript. All authors interpreted the data, drafted and revised the manuscript, code, and results critically. All authors read and approved the final version of the manuscript. SB is the guarantor of the paper.

Competing interest: The authors completed the Unified Competing Interest form at www.icmje.org/coi_disclosure.pdf (available upon request from the corresponding author), and declare no conflicts of interest.

1 Oram S, Khalifeh H, Howard LM. Violence against women and mental health. Lancet Psychiatry. 2017;4:159-70. Medline:27856393 doi:10.1016/S2215-0366(16)30261-9

2 World Health Organization. Global and regional estimates of violence against women: prevalence and health effects of intimate partner violence and non-partner sexual violence. Geneva: WHO; 2013. Available: https://www.who.int/ reproductivehealth/publications/violence/9789241564625/en/. Accessed: 21 September 2019.

3 World Health Organization. Violence against women. Key facts. Available: http://www.who.int/en/news-room/fact-sheets/ detail/violence-against-women. Accessed: 21 September 2019.

4 Garcia-Moreno C, Jansen HA, Ellsberg M, Heise L, Watts CH. Prevalence of intimate partner violence: findings from the WHO multi-country study on women's health and domestic violence. Lancet. 2006;368:1260-9. Medline:17027732 doi:10.1016/S0140-6736(06)69523-8

5 Paras ML, Murad MH, Chen LP, Goranson EN, Sattler AL, Colbenson KM, et al. Sexual abuse and lifetime diagnosis of somatic disorders: a systematic review and meta-analysis. JAMA. 2009;302:550-61. Medline:19654389 doi:10.1001/ jama.2009.1091

6 Jonas S, Bebbington P, McManus S, Meltzer H, Jenkins R, Kuipers E, et al. Sexual abuse and psychiatric disorders in England: results from the 2007 Adult Psychiatric Morbidity Survey. Psychol Med. 2011;41:709-19. Medline:20534178 doi:10.1017/S003329171000111X

7 Chen LP, Murad MH, Paras ML, Colbenson KM, Sattler AL, Goranson EN, et al. Sexual abuse and lifetime diagnosis of psychiatric disorders: Systematic review and meta-analysis. Mayo Clin Proc. 2010;85:618. Medline:20458101 doi: $10.4065 / \mathrm{mcp} .2009 .0583$

8 Lindert J, von Ehrenstein O, Grashow R, Gal G, Braehler E, Weisskopf MG. Sexual and physical abuse in childhood is associated with depression and anxiety over the life course: systematic review and meta-analysis. Int J Public Health. 2014;59:359-72. Medline:24122075 doi:10.1007/s00038-013-0519-5

9 Nerum H, Halvorsen L, Ojan P, Sorlie T, Straume B, Blix E. Birth outcomes in primiparous women who were raped as adults: a matched controlled study. BJOG. 2010;117:288-94. Medline:20015304 doi:10.1111/j.1471-0528.2009.02454.x

10 Henriksen L, Schei B, Vangen S, Lukasse M. Sexual violence and mode of delivery: a population-based cohort study. BJOG. 2014;121:1237-44. Medline:24939396 doi:10.1111/1471-0528.12923

11 Nerum H, Halvorsen L, Straume B. Different labour outcomes in primiparous women that have subjected to childhood sexual abuse or rape in adulthood: a case-control study in a clinical cohort. BJOG. 2013;120:487-95. Medline:23157417 doi:10.1111/1471-0528.12053

12 Finnbogadóttir H, Dejin-Karlsson E, Dykes A-K. A multi-centre cohort study shows no association between experienced violence and labour dystocia in nulliparous women at term. BMC Pregnancy Childbirth. 2011;11:14. Medline:21338523 doi:10.1186/1471-2393-11-14

13 Gisladottir A, Luque-Fernandez MA, Harlow BL, Gudmundsdottir B, Jonsdottir E, Bjarnadottir RI, et al. Obstetric outcomes of mothers previously exposed to sexual violence. PLoS One. 2016;11:e0150726. Medline:27007230 doi:10.1371/ journal.pone.0150726

14 Steegers EA, von Dadelszen P, Duvekot JJ, Pjinenborg R. Pre-eclampsia. Lancet. 2010;376:631-44. Medline:20598363 doi:10.1016/S0140-6736(10)60279-6

15 Venkatesha S, Toporsian M, Lam C, Hanai J, Mammoto D, Kim YM, et al. Soluble endoglin contributes to the pathogenesis of preeclampsia. Nat Med. 2006;12:642-9. Medline:16751767 doi:10.1038/nm1429

16 Silverman JG, Decker MR, Reed E, Raj A. Intimate partner violence victimization prior to and during pregnancy among women residing in 26 U.S. states: associations with maternal and neonatal health. Am J Obstet Gynecol. 2006;195:1408. Medline:16813751 doi:10.1016/j.ajog.2005.12.052

17 Kearney MH, Haggerty LA, Munro BH, Hawkins JW. Birth outcomes and maternal morbidity in abused pregnant women with public versus private health insurance. J Nurs Scholarsh. 2003;35:345-9. Medline:14735677 doi:10.1111/j.15475069.2003.00345.x

18 Sanchez SE, Qiu C, Perales MT. Intimate partner violence (IPV) and preeclampsia among Peruvian women. Eur J Obstet Gynecol Reprod Biol. 2008;137:50-5. Medline:17600610 doi:10.1016/j.ejogrb.2007.05.013 
19 Walsh K, Galea S, Koenen KC. Mechanisms Underlying Sexual Violence Exposure and Psychosocial Sequelae; a Theoretical and Empirical Review. Clin Psychol (New York). 2012;19:260-75. Medline:25762853 doi:10.1111/cpsp.12004

20 Jewkes R, Corboz J, Gibbs A. Trauma exposure and IPV experienced by Afghan women: Analysis of the baseline of a randomized controlled trial. PLoS One. 2018;13:e0201974. Medline:30303956 doi:10.1371/journal.pone.0201974

21 Clark CJ, Everson-Rose SA, Suglia SF, Btoush R, Alonso A, Haj-Yahia M. Association between exposure to political violence and intimate partner violence in the occupied Palestinian territory: a cross sectional study. Lancet. 2010;375:3106. Medline:20109958 doi:10.1016/S0140-6736(09)61827-4

22 Tankard ME, Paluck EL, Prentice DA. The effect of a savings intervention on women's intimate partner violence victimization: heterogeneous findings from a randomized controlled trial in Colombia. BMC Womens Health. 2019;19:17. Medline:30683076 doi:10.1186/s12905-019-0717-2

23 Aguero JM. Prevalence of violence against women among different ethnic groups in Peru. Inter-American Development Bank. 2018. Available: https://publications.iadb.org/en/prevalence-violence-against-women-among-different-ethnicgroups-peru. Accessed: 23 September 2019.

24 Raj A, McDougal L. Sexual violence and rape in India. Lancet. 2014;383:865. Medline:24607092 doi:10.1016/S01406736(14)60435-9

25 Théra JP, Soumah M, Traore T, Toure M, Traore M, Sow ML. Epidemiological, clinical and judicial aspects of sexual assault in Bamako (Mali). Sante Publique. 2014;26:123-9. Medline:24893524

26 Gender-Based Violence Prevention and Response. UNFPA Philippines. Available: https://philippines.unfpa.org/en/ node/15307. Accessed: 23 September 2019.

27 Ansari N, Manalai P, Maruf F, Currie S, Stekelenburg J, van Roosmalen J, et al. Quality of care in early detection and management of pre-eclampsia/eclampsia in health facilities in Afghanistan. BMC Pregnancy Childbirth. 2019;19:36. Medline:30658606 doi:10.1186/s12884-018-2143-0

28 Nobis PN, Hajong A. Eclampsia in India Through the Decades. J Obstet Gynaecol India. 2016;66 Suppl 1:172-6. Medline:27651598 doi:10.1007/s13224-015-0807-5

29 Bellizzi S, Sobel H, Ali M. Signs of eclampsia during singleton deliveries and early neonatal mortality in low- and middle-income countries from three WHO regions. Int J Gynaecol Obstet. 2017;139:50-4. Medline:28704570 doi:10.1002/ ijgo. 12262

30 Rustein SO, Rojas G. Guide to DHS Statistics. Calverton, MD: ORC Macro, MEASURE DHS+,2006. Available: http:// www.ophi.org.uk/wp-content/uploads/OPHI-HDCA-SS2012-Guide_DHS_Statistics.pdf. Accessed: 24 September 2019.

31 Heise LL, Kotsadam A. Cross-national and multilevel correlates of partner violence: an analysis of data from population-based surveys. Lancet Glob Health. 2015;3:e332-40. Medline:26001577 doi:10.1016/S2214-109X(15)00013-3

32 Durevall D, Lindskog A. Intimate partner violence and HIV in ten sub-Saharan African countries: what do the Demographic and Health Surveys tell us? Lancet Glob Health. 2015;3:e34-43. Medline:25539967 doi:10.1016/S2214109X(14)70343-2

33 Kisho S. Domestic violence measurement in the demographic and health surveys: the history and the challenges. Expert paper for the UN Division for the Advancement of Women, Geneva; 2005. Available: https://pdfs. semanticscholar.org/950b/55a5c5c78be9ac40a3bdf91f7957d983e410.pdf?_ga=2.65403885.2136021170.15732218161676481552.1573221816. Accessed: 12 September 2019.

34 Francisco C, Wright D, Benko Z, Syngelaki A, Nicolaides KH. Hidden high rate of pre-eclampsia in twin compared with singleton pregnancy. Ultrasound Obstet Gynecol. 2017;50:88-92. Medline:28317207 doi:10.1002/uog.17470

35 World Health Organization. Health care for women subjected to intimate partner violence or sexual violence. Geneva: WHO; 2014

36 Corsi DJ, Neuman M, Finlay JE, Subramanian SV. Demographic and Health surveys: a profile. Int J Epidemiol. 2012;41:1602-13. Medline:23148108 doi:10.1093/ije/dys184

37 Ackerson LK, Kawachi I, Barbeau EM, Subramanian SV. Effects of individual and proximate educational context on intimate partner violence: a population-based study of women in India. Am J Public Health. 2008;98:507-14. Medline:18235066 doi:10.2105/AJPH.2007.113738

38 Hindin MJ, Kishor S, Ansara DL. Intimate partner Violence among Couples in 10 DHS Countries: Predictors and Health Outcomes. Calverton, MD: Macro International Inc; 2008.

39 Hindin MJ, Adair LS. Who's at risk? Factors associated with intimate partner violence in the Philippines. Soc Sci Med. 2002;55:1385-99. Medline:12231016 doi:10.1016/S0277-9536(01)00273-8

40 Goodwin MM, Gazmararian JA, Johnson CH, Gilbert BC, Saltzman LE. Pregnancy intendness and physical abuse around the time of pregnancy: findings from the pregnancy risk assessment monitoring system, 1996-1997. PRAMS Working Group. Pregnancy Risk Assessment Monitoring System. Matern Child Health J. 2000;4:85-92. Medline:10994576 doi:10.1023/A:1009566103493

41 Bellizzi S, Sobel HL, Mathai M, Temmerman M. Does place and attendance at birth improve early neonatal mortality? Secondary analysis of nine Demographic and Health Surveys. BJOG. 2017;124:1558-65. Medline:27862850 doi:10.1111/1471-0528.14422

42 Chai J, Fink G, Kaaya S, Danaei G, Fawzi W, Ezzati M, et al. Association between intimate partner violence and poor child growth: results from 42 demographic and health surveys. Bull World Health Organ. 2016;94:331-9. Medline:27147763 doi:10.2471/BLT.15.152462

43 Donner A, Klar N. Methods for comparing event rates in intervention studies when the unit of allocation is a cluster. Am J Epidemiol. 1994;140:279-89. Medline:8030631 doi:10.1093/oxfordjournals.aje.a117247 
44 Stata Corp. Statistical software: release 13 SE [Computer program]. College Station, TX: Stata Corp., 2013.

45 Souza JP, Cecatti JG, Pacagnella RC, Giavarotti TM, Parpinelli MA, Camargo RS, et al. Development and validation of a questionnaire to identify severe maternal morbidity in epidemiological surveys. Reprod Health. 2010;7:16. Medline:20663159 doi:10.1186/1742-4755-7-16

46 Coker AL, Sanderson M, Dong B. Partner violence during pregnancy and risk of adverse pregnancy outcomes. Paediatr Perinat Epidemiol. 2004;18:260-9. Medline:15255879 doi:10.1111/j.1365-3016.2004.00569.x

47 Hall M, Chappell LC, Parnell BL, Seed PT, Bewley S. Association between intimate partner violence and termination of pregnancy: a systematic review and meta-analysis. PLoS Med. 2014;11:e1001581. Medline:24409101 doi:10.1371/ journal.pmed.1001581

48 Yost NP, Bloom SL, McIntire DD, Leveno KJ. A prospective observational study of domestic violence during pregnancy. Obstet Gynecol. 2005;106:61-5. Medline:15994618 doi:10.1097/01.AOG.0000164468.06070.2a

49 Wiemann CM, Agurcia CA, Berenson AB, Volk RJ, Rickert VI. Pregnant adolescents: experiences and behaviors associated with physical assaults by an intimate partner. Matern Child Health J. 2000;4:93-101. Medline:10994577 doi:10.1023/A:1009518220331

50 Heimstad R, Dahloe R, Laache I, Skogvoll E, Schei B. Fear of childbirth and history of abuse: implications for pregnancy and delivery. Acta Obstet Gynecol Scand. 2006;85:435-40. Medline:16612705 doi:10.1080/00016340500432507

51 Eberhard-Gran M, Slinning K, Eskild A. Fear during labor: the impact of sexual abuse in adult life. J Psychosom Obstet Gyneacol. 2008;29:258-61. Medline:18608823 doi:10.1080/01674820802075998

52 Bilano VL, Ota E, Ganchimeg T, Mori R, Souza JP. Risk factors of pre-eclampsia/eclampsia and its asverse outcomes in lowand middle-income countries: a WHO secondary analysis. PLoS One. 2014;9:e91198. Medline:24657964 doi:10.1371/ journal.pone.0091198

53 Riley EH, Wright RJ, Jun HJ, Hibert EN, Rich-Edwards JW. Hypertension in adult survivors of child abuse: observations from the Nurses' Health Study II. J Epidemiol Community Health. 2010;64:413-8. Medline:20445210 doi:10.1136/ jech.2009.095109

54 Roberts AL, Lyall K, Rich-Edwards JW, Ascherio A, Weisskopf MG. Association of maternal exposure to childhood abuse with elevated risk for autism in offspring. JAMA Psychiatry. 2013;70:508-15. Medline:23553149 doi:10.1001/jamapsychiatry.2013.447

55 Slopen N, Kubransky L, McLaughlin K, Koenen KC. Childhood adversity and inflammatory processes in youth: a prospective study. Psychoneuroendocrinology. 2013;38:188-200. Medline:22727478 doi:10.1016/j.psyneuen.2012.05.013

56 Spitzer C, Bouchain M, Winkler LY, Wingenfeld K, Gold SM, Grabe HJ, et al. Childhood trauma in multiple sclerosis: A case-control study. Psychosom Med. 2012;74:312-8. Medline:22408134 doi:10.1097/PSY.0b013e31824c2013

57 Boeckel MG, Viola TW, Daruy-Filho L, Martinez M, Grassi-Oliveira R. Intimate partner violence is associated with increased maternal hair cortisol in mother-child dyads. Compr Psychiatry. 2017;72:18-24. Medline:27693887 doi:10.1016/j. comppsych.2016.09.006

58 Heller M, Roberts ST, Masese L, Ngina J, Chohan N, Chohan V, et al. Gender-based violence, physiological stress, and inflammation: A cross-sectional study. J Womens Health (Larchmt). 2018;27:1152-61. Medline:29630431 doi:10.1089/ jwh.2017.6743

59 Brue T, Amodru V, Castinetti F. Management of endocrine disease: Management of Cushing's syndrome during pregnancy: solved and unsolved questions. Eur J Endocrinol. 2018;178:R259-66. Medline:29523633 doi:10.1530/EJE-17-1058

60 Vianna P, Bauer ME, Dornfeld D, Chies JA. Distress conditions during pregnancy may lead to pre-eclampsia by increasing cortisol levels and altering lymphocyte sensitivity to glucocorticoids. Med Hypotheses. 2011;77:188-91. Medline:21550175 doi:10.1016/j.mehy.2011.04.007

61 Kinney DK, Miller M, Crowley DJ, Huang E, Gerber E. Autism prevalence following prenatal exposure to hurricanes and tropical storms in Louisiana. J Autism Dev Disord. 2008;38:481-8. Medline:17619130 doi:10.1007/s10803-007-0414-0

62 Causevic M, Mohaupt M. 11beta-Hydroxysteroid dehydrogenase type 2 in pregnancy and preeclampsia. Mol Aspects Med. 2007;28:220-6. Medline:17532462 doi:10.1016/j.mam.2007.04.003

63 Hogg K, Blair JD, McFadden DE, von Dadelszen P, Robinson WP. Early onset pre-eclampsia is associated with altered DNA methylation of cortisol-signalling and steroidogenic genes in the placenta. PLoS One. 2013;8:e62969. Medline:23667551 doi:10.1371/journal.pone.0062969

64 Qiu C, Williams MA, Calderon-Margalit R, Cripe SM, Sorensen TK. Preeclampsia risk in relation to maternal mood and anxiety disorders diagnosed before or during early pregnancy. Am J Hypertens. 2009;22:397-402. Medline:19197246 doi:10.1038/ajh.2008.366

65 World Health Organization. Responding to intimate partner violence and sexual violence against women: WHO clinical and policy guidelines. Geneva: WHO; 2013. Available: https://apps.who.int/iris/bitstream/handle/10665/85240/9789241548595_ eng.pdf;jsessionid=0D5C21EF2FC34123F929CB86D9CBF97E?sequence=1. Accessed: 12 September 2019. 